\title{
Neuropeptide S Activates Paraventricular Oxytocin Neurons to Induce Anxiolysis
}

\author{
Thomas Grund, ${ }^{1}$ Stephanie Goyon, ${ }^{2}$ Yuting Li, ${ }^{3}$ Marina Eliava, ${ }^{4}$ Haikun Liu, ${ }^{3}{ }^{\oplus}$ Alexandre Charlet, ${ }^{2,5}$ Valery Grinevich, ${ }^{4 *}$ \\ and Inga D. Neumann ${ }^{1 *}$ \\ 1Department of Behavioral and Molecular Neurobiology, Regensburg Center of Neuroscience, University of Regensburg, 93040 Regensburg, Germany, \\ 2Institute of Cellular and Integrative Neurosciences UPR3212, Centre National de la Recherche Scientifique, University of Strasbourg, 67084 Strasbourg, \\ France, ${ }^{3}$ Division of Molecular Neurogenetics, German Cancer Research Center, DKFZ-ZMBH Alliance, Im Neuenheimer Feld 280, Heidelberg 69120, \\ Germany, ${ }^{4}$ Division of Neuropeptides (V078), German Cancer Research Center, Central Institute of Mental Health, CellNetwork Cluster of Excellence, \\ University of Heidelberg, 69120 Heidelberg, Germany, and ${ }^{5}$ University of Strasbourg, Institute for Advanced Study, 67084 Strasbourg, France
}

Neuropeptides, such as neuropeptide S (NPS) and oxytocin (OXT), represent potential options for the treatment of anxiety disorders due to their potent anxiolytic profile. In this study, we aimed to reveal the mechanisms underlying the behavioral action of NPS, and present a chain of evidence that the effects of NPS within the hypothalamic paraventricular nucleus (PVN) are mediated via actions on local OXT neurons in male Wistar rats. First, retrograde studies identified NPS fibers originating in the brainstem locus coeruleus, and projecting to the PVN. FACS identified prominent NPS receptor expression in PVN-OXT neurons. Using genetically encoded calcium indicators, we further demonstrated that NPS reliably induces a transient increase in intracellular $\mathrm{Ca}^{2+}$ concentration in a subpopulation of OXT neurons, an effect mediated by NPS receptor. In addition, intracerebroventricular (i.c.v.) NPS evoked a significant somatodendritic release of OXT within the PVN as assessed by microdialysis in combination with a highly sensitive radioimmunoassay. Finally, we could show that the anxiolytic effect of NPS seen after i.c.v. or intra-PVN infusion requires responsive OXT neurons of the PVN and locally released OXT. Thus, pharmacological blockade of OXT receptors as well as chemogenetic silencing of OXT neurons within the PVN prevented the effect of synthetic NPS. In conclusion, our results indicate a significant role of the OXT system in mediating the effects of NPS on anxiety, and fill an important gap in our understanding of brain neuropeptide interactions in the context of regulation of emotional behavior within the hypothalamus.

Key words: anxiety; DREADD; GCaMP6s; microdialysis; neuropeptide S; oxytocin

Significance Statement

Given the rising scientific interest in neuropeptide research in the context of emotional and stress-related behaviors, our findings demonstrate a novel intrahypothalamic mechanism involving paraventricular oxytocin neurons that express the neuropeptide $S$ receptor. These neurons respond with transient $\mathrm{Ca}^{2+}$ increase and somatodendritic oxytocin release following neuropeptide $\mathrm{S}$ stimulation. Thereby, oxytocin neurons seem essential for neuropeptide S-induced anxiolysis, as this effect was blocked by pharmacological and chemogenetic inhibition of the oxytocin system.

\section{Introduction}

Anxiety disorders have a lifetime prevalence of $\sim 28 \%$ (Gross and Hen, 2004; Kessler et al., 2005); however, specific and efficient

Received Aug. 1, 2017; revised 0ct. 27, 2017; accepted 0ct. 31, 2017.

Author contributions: T.G., A.C., V.G., and I.D.N. designed research; T.G., S.G., Y.L., M.E., H.L., A.C., and I.D.N. performed research; T.G. and I.D.N. contributed unpublished reagents/analytic tools; T.G., S.G., Y.L., M.E., H.L., and I.D.N. analyzed data; T.G., A.C., V.G., and I.D.N. wrote the paper.

This work was supported by German Research Foundation (Deutsche Forschungsgemeinschaft), German Ministry of Education and Research (Bundesministerium für Bildung und Forschung), EU (FemNatCD), and Bayerische Forschungsstiftung to I.D.N.; Chica and Heinz Schaller Research Foundation, Fritz Thyssen Foundation, German Research Foundation (Deutsche Forschungsgemeinschaft) within the Collaborative Research Center (Sonderforschungsbereich) 1134 and 1158, and Human Frontiers Science Program RGP0019/2015 to V.G.;PHC PROCOP program therapeutic strategies are still required. The nonapeptide oxytocin (OXT) and the recently discovered neuropeptide S (NPS), a 20-amino acid neuropeptide, represent powerful therapeutic candidates due to their potent anxiolytic activity (Xu et al., 2004;
32975SA (DAAD and Campus France) and ANR-Deutsche Forschungsgemeinschaft Grant GR 3619/701 to V.G. and A.C.; and University of Strasbourg Institute for Advanced Study Fellowship 2014-17, Fyssen Foundation Research Grant 2015, and National Alliance for Research on Schizophrenia and Depression Young Investigator Grant 24821 to A.C. We thank Dr. Harold Gainer (National Institutes of Health, Bethesda, MD) for kindly providing the OXT antibody; Dr. Maurice Manning (Toledo, Ohio) for generously providing the OXTR-A; Drs. Kay Jüngling and Hans-Christian Pape (Institute of Physiology, Münster, Germany) for advice on applications of NPS and SHA-68; Rodrigue Maloumby and Andrea Havasi for excellent technical assistance; and Judith Müller and Elke Lederer for preparation of rAAVs and help with FACS. 
Pape et al., 2010; Neumann and Landgraf, 2012; Slattery et al., 2015; Neumann and Slattery, 2016). However, the OXT and NPS systems represent, so far, two separate neuropeptide systems, and studies for possible interactions at neuronal level are lacking.

In addition to the hypothalamic supraoptic (SON) and accessory nuclei, the main site of OXT synthesis is the paraventricular nucleus (PVN) (Swanson and Sawchenko, 1983), where OXT is locally released in response to various stressful stimuli (Neumann, 2007), and where it exerts anxiolytic effects as shown in male and female rats (Blume et al., 2008; Jurek et al., 2012; van den Burg et al., 2015). The PVN is a major integrative center of the brain coordinating behavioral and physiological responses, for example, to stress and fearful stimuli (Knobloch et al., 2012; Neumann and Landgraf, 2012; Anthony et al., 2014). Accordingly, the rodent PVN receives afferents from various limbic regions and from noradrenergic neurons located in the locus coeruleus (LC) (Swanson and Sawchenko, 1980; Jones and Yang, 1985; Loughlin et al., 1986) that also harbors a cluster of predominantly glutamatergic neurons synthesizing NPS (Xu et al., 2007). Prominent NPS-immunopositive projections to the PVN have so far been described in C57BL/6 mice (Clark et al., 2011).

Whereas NPS-synthesizing neurons in rats are exclusively found in distinct brainstem regions, such as the LC, Barrington's nucleus, lateral parabrachial nucleus, and the principal sensory trigeminal nucleus, the NPS receptor (NPSR) is widely distributed in the rat brain (Xu et al., 2007). There is evidence for NPSR expression in areas involved in olfaction, modulation of sleepwake cycle and food intake, and limbic brain regions relevant for the processing of fear, anxiety, and stress responses, such as the amygdala and the hypothalamus, specifically in the PVN (Xu et al., 2007; Leonard and Ring, 2011).

In addition to robust anxiolytic actions, NPS and OXT share various other behavioral and physiological effects, such as the reversal of social fear (Zoicas et al., 2014; Zoicas et al., 2016), the attenuation of aggressive-like behavior (Beiderbeck et al., 2014; de Jong et al., 2014; Ruzza et al., 2015), as well as anorexic (Olson et al., 1991; Beck et al., 2005; Smith et al., 2006) and antinociceptive effects (Li et al., 2009; Eliava et al., 2016). Moreover, both NPS and OXT neurons are responsive to acute stress (Neumann, 2007; Ebner et al., 2011; Jüngling et al., 2012; Torner et al., 2017) and have the capacity to regulate the physiological activity of the hypothalamo-pituitary-adrenal axis (Neumann et al., 2006; Smith et al., 2006; Jurek et al., 2015; Torner et al., 2017).

These functional similarities, together with the neuroanatomical overlapping of the NPS and OXT systems (Swanson and Sawchenko, 1983; Xu et al., 2007; Yoshida et al., 2009), led us to hypothesize that NPS effects are mediated via OXT neurons within the PVN of male Wistar rats. Our present results reveal that NPS specifically activates NPSR-expressing OXT neurons within the PVN indicated by increased $\mathrm{Ca}^{2+}$ mobilization and local somatodendritic OXT release. Moreover, we show that pharmacological and chemogenetic inhibition of OXT neurons blocks NPS-induced anxiolysis. These findings provide the first evidence for an intrahypothalamic mechanism involving NPSRexpressing OXT neurons in the potent anxiolytic profile of NPS.

The authors declare no competing financial interests.

*V.G. and I.D.N. contributed equally to this work as senior authors.

Correspondence should be addressed to Dr. Inga D. Neumann, University of Regensburg, Department of Behavioural and Molecular Neurobiology, Universitätsstraße 31, 93053 Regensburg, Germany. E-mail: inga.neumann@ur.de.

https://doi.org/10.1523/JNEUROSCI.2161-17.2017

Copyright $\odot 2017$ the authors

\section{Materials and Methods}

Animals. Male Wistar rats (230-250 g, Charles River Laboratories) were housed under standard laboratory conditions (12:12 h light/dark cycle, lights on at $0700,21^{\circ} \mathrm{C}-23^{\circ} \mathrm{C}, 55 \%$ humidity, food/water ad libitum). Rats were allowed at least 1 week of habituation before they were used for surgical procedures. All experiments were performed between 0800 and 1300 in accordance with the Guide for the care and use of laboratory animals by the National Institutes of Health, and were approved by the governments of the Oberpfalz and Baden-Württemberg.

Surgical procedures. For stereotaxic gene delivery, or implantation of guide cannulas and microdialysis probes, rats were injected subcutaneously with the analgesic drug Buprenorphine (Bayer, $0.05 \mathrm{mg} / \mathrm{kg}$ ) and the antibiotic Baytril (Baxter, $10 \mathrm{mg} / \mathrm{kg}$ ) $30 \mathrm{~min}$ before the start of the surgery. All stereotaxic procedures were performed under isoflurane anesthesia and semisterile conditions as described in detail previously (Slattery et al., 2015; van den Burg et al., 2015; Eliava et al., 2016). All coordinates used are based on the rat brain atlas (Paxinos and Watson, 1998).

For viral microinfusion into the left and right PVN (anteroposterior, $-1.8 \mathrm{~mm}$; mediolateral, $\pm 0.3 \mathrm{~mm}$; dorsoventral, $-8.0 \mathrm{~mm}$ ) and SON (anteroposterior, $-1.4 \mathrm{~mm}$; mediolateral, $\pm 1.7 \mathrm{~mm}$; dorsoventral, -9.0 $\mathrm{mm}$ ), respectively, we used a $5 \mu \mathrm{l}$ calibrated micropipette (VWR, inner diameter, $0.3 \mathrm{~mm}$ ), which was pulled to create a long narrow shank. The micropipette shaft was marked with a $1 \mathrm{~mm}$ scale that corresponds to a volume of $\sim 70 \mathrm{nl}$. In total, $280 \mathrm{nl}$ of cell-type specific recombinant adeno-associated viral vectors (rAAVs) were infused slowly into each PVN by pressure infusion. After the infusion, the micropipette was kept in place for $3 \mathrm{~min}$ to ensure adequate $\mathrm{rAAV}$ diffusion. The drill hole in the skull was closed using bone wax (Ethicon), and the wound was sutured using sterile nylon material.

For intracerebroventricular (i.c.v.) infusions, a 12-mm-long 21-G guide cannula was stereotaxically placed $2 \mathrm{~mm}$ above the lateral ventricle (anteroposterior, $-1.0 \mathrm{~mm}$; mediolateral, $-1.6 \mathrm{~mm}$; dorsoventral, -2.0 $\mathrm{mm})$. For bilateral intra-PVN infusions, $12-\mathrm{mm}$-long $23-\mathrm{G}$ guide cannulas were implanted $2 \mathrm{~mm}$ above the left and right PVN (anteroposterior, $-1.4 \mathrm{~mm}$; mediolateral, $1.8 \mathrm{~mm}$; $-2.1 \mathrm{~mm}$; dorsoventral, -6.3 $\mathrm{mm}$; angle: $10^{\circ}$ ). To monitor OXT locally released within the PVN, a $\mathrm{U}$-shaped microdialysis probe was implanted into the right PVN (anteroposterior, $-1.4 \mathrm{~mm}$; mediolateral, $1.8 \mathrm{~mm}$; dorsoventral, $-8.3 \mathrm{~mm}$; angle: $10^{\circ}$ ). Both guide cannulas and microdialysis probes targeting the PVN were implanted using an angle of $10^{\circ}$ to avoid sagittal sinus damage. All implants were fixed to two stainless-steel screws using dental cement. Rats were housed singly after surgery, allowed to recover for $2 \mathrm{~d}$ (microdialysis) or $5 \mathrm{~d}$ (central infusions), and handled daily to minimize nonspecific stress responses at the day of experiment. Guide cannulas were closed using dummy cannulas, which were cleaned daily during the handling procedure with $70 \%$ ethanol and sterile water.

Retrograde tracing of NPS-immunoreactive neurons. Cholera toxin subunit B coupled to AlexaFluor-488 (CTB-488, ThermoScientific, $0.5 \mu \mathrm{l}$, $5 \mu \mathrm{g} / \mu \mathrm{l}$ in PBS, $\mathrm{pH} 7.4$ ) was infused bilaterally into the PVN (anteroposterior, $-1.8 \mathrm{~mm}$; mediolateral, $\pm 0.3 \mathrm{~mm}$; dorsoventral, $-8.0 \mathrm{~mm}$ ) using a calibrated micropipette under isoflurane anesthesia. The infusion system was kept in place for 3 min to ensure adequate tracer diffusion. Animals were housed singly for $5 \mathrm{~d}$ until transcardial perfusion. NPS (1:500, Abcam, ab18252); OXT (1:500, p38 mouse monoclonal) (BenBarak et al., 1985) and CTB-488 were visualized in $40 \mu \mathrm{m}$ coronal brain slices containing the PVN and LC, respectively, using Leica DM5000B.

Preparation of samples and FACS analysis. Rats were injected with celltype specific $\mathrm{AAV}_{1 / 2}$ OXTpr-Venus into the SON and PVN to express Venus in OXT neurons (Knobloch et al., 2012). Three weeks later, rats were killed, and their brains were removed and sectioned into large pieces using rat brain matrix (1-mm thick sections). SON and PVN were bilaterally extracted by micro-punch technique. FACS method of neuronal cells was modified from established protocols (Lobo et al., 2006; GuezBarber et al., 2012). The tissue was placed in $1 \mathrm{ml}$ of dissection buffer containing the following (in $\mathrm{mm}$ ): 150 sucrose, $125 \mathrm{NaCl}, 3.5 \mathrm{KCl}, 1.2$ $\mathrm{NaH}_{2} \mathrm{PO}_{4}, 2.4 \mathrm{CaCl}_{2}, 1.3 \mathrm{MgCl}_{2}, 6.65$ glucose, and 2 HEPES, pH 6.9 (osmolarity $326 \mathrm{~mm}$, all from Sigma) (Li et al., 2015) and minced with 
Table 1. List of primers used for mRNA expression studies in rats

\begin{tabular}{ll}
\hline Primer/probe & $5^{\prime}-3^{\prime}$ \\
\hline NPSR (forward) & TCCAATGGTGAGGTACAGTGC \\
NPSR (reverse) & ACACCAGAAAGGCAACGATG \\
Beta actin (forward) & TCCTGTGCATCCATGAAAC \\
Beta actin (reverse) & ACAGCACTGTGTTGGCATAG \\
\hline
\end{tabular}

razor blades on an ice-cold glass plate. Later, dissection buffer was replaced with $1 \mathrm{ml}$ of Accutase (A6964, Sigma-Aldrich), and tubes were rotated for $30 \mathrm{~min}$ at $4^{\circ} \mathrm{C}$. Then, tissue pieces were rinsed twice in ice-cold Neurobasal-A complete medium: 50\% Neurobasal-A, 50\% Leibovitz L-15 medium (31415, Invitrogen), 2\% B27 supplement (17504044, Invitrogen), DNase I $0.001 \%$, and $0.5 \%$ penicillin-streptomycin (15140122, Invitrogen). To dissociate the cells, tissue pieces were triturated in $1 \mathrm{ml}$ Neurobasal-A complete medium with a Pasteur pipette. Supernatant containing cloudy dissociated cells were transferred to a new $15 \mathrm{ml} \mathrm{Fal-}$ con tube on ice. Cells were filtered with $70 \mu \mathrm{m}$ cell strainer and centrifuged for $3 \mathrm{~min}$ at $430 \times g$ through a three-step density gradient of Percoll (P1644, Sigma). Cells at the bottom layer were collected for later use. For FACS of OXT-Venus ${ }^{+}$cells, propidium iodide $(20 \mu \mathrm{g} / \mathrm{ml})$ was used to label dead cells just before sorting. Subsequently, FACS-based purifications of Venus ${ }^{+}$and Venus ${ }^{-}$viable cells were sorted into RNasefree tubes with RNA extraction lysis buffer by BD FACSAria II at Flow Cytometry Core Facility at DKFZ. Negative controls were done at the same time.

$q R T-P C R$. Total RNAs were extracted and purified from FACS-sorted cells with the RNeasy Mini kit or RNeasy FFPE Kit (QIAGEN). RNA was transcribed into cDNA using random primers (dN6, Roche) and M-MLV reverse transcriptase (Promega). cDNA were quantified by using SYBR gene expression assays (QIAGEN) or TaqMan Probe with Absolute Blue qPCR Rox mix (ThermoFisher), on the CFX96 Real-time System (Bio-Rad). Standard curves were generated, and each experiment was performed in duplicate. Relative transcript concentrations were calculated using the $2^{(-\Delta \Delta \mathrm{Ct})}$ method (Livak and Schmittgen, 2001) in relation to $\beta$-actin as reference gene. Primers and probes used for $\mathrm{qRT}$ PCR are listed in Table 1.

$\mathrm{Ca}^{2+}$ imaging in PVN-OXT neurons. AAV $\mathrm{A}_{1 / 2}$ OXTpr-GCaMP6s was infused bilaterally into the PVN. Three weeks later, animals were anesthetized using a ketamine/xylazine mixture (Imalgene $90 \mathrm{mg} / \mathrm{kg}$, Rompun, $10 \mathrm{mg} / \mathrm{kg}$ ) administered intraperitoneally.

Transcardial perfusion was then performed using NMDG-based ACSF (composition in mu as follows): $93 \mathrm{NMDG}, 2.5 \mathrm{KCl}, 1.25 \mathrm{NaH}_{2} \mathrm{PO}_{4}, 30$ $\mathrm{NaHCO}_{3}, 10 \mathrm{MgSO}_{4}, 0.5 \mathrm{CaCl}_{2}, 20 \mathrm{HEPES}, 25 \mathrm{D}$-glucose, $5 \mathrm{~L}$ ascorbic acid, 2 thiourea, 3 sodium pyruvate, $10 \mathrm{~N}$-acetyl-L-cysteine, and 2 kynurenic acid, pH 7.4 (300-310 mOsm/l, continuously bubbled in $95 \% \mathrm{O}_{2}-5 \%$ $\mathrm{CO}_{2}$ gas). Next, $300-\mu \mathrm{m}$ thick coronal slices containing the PVN were collected using a Leica VT1000s vibratome. Next, brain slices were placed in a room-temperature holding chamber with normal ACSF, for a minimum of $1 \mathrm{~h}$ before the conduction of any experiments. In $\mathrm{Ca}^{2+}$ imaging experiments, slices were transferred to an immersion recording chamber and superfused at a rate of $2 \mathrm{ml} / \mathrm{min}$ with normal ACSF (composition in mM as follows): $124 \mathrm{NaCl}, 2.5 \mathrm{KCl}, 1.25 \mathrm{NaH}_{2} \mathrm{PO}_{4}, 26 \mathrm{NaHCO}_{3}, 2$ $\mathrm{MgSO}_{4}, 2 \mathrm{CaCl}_{2}$, and $15 \mathrm{D}$-glucose (300-310 mOsm/l, adjusted for $\mathrm{pH}$ values of 7.4 with $\mathrm{HCl}$ and continuously bubbled in $95 \% \mathrm{O}_{2}-5 \% \mathrm{CO}_{2}$ gas) unless indicated otherwise.

Ex vivo $\mathrm{Ca}^{2+}$ imaging recordings. Spinning disk confocal microscope used to perform OXT neuron $\mathrm{Ca}^{2+}$ imaging was composed of a Zeiss Axio examiner microscope with a $20 \times$ water-immersion objective (numerical aperture of 1.0), mounted with a X-Light Confocal unit, CRESTOPT spinning disk. Images were acquired at $5 \mathrm{~Hz}$ with an optiMOS sCMOS camera (Qimaging). Cells within a confocal plane were illuminated for 100-150 ms for each wavelength (GCaMP6s: $475 \mathrm{~nm}$ ) using a Spectra 7 LUMENCOR. The different hardware elements were synchronized through the MetaFluor software (Molecular Devices), which was also used for online and offline quantitative fluorescence analysis. OXT neuron $\mathrm{Ca}^{2+}$ levels were measured in hand-drawn regions of interest (ROIs) comprising the cell body. $\left[\mathrm{Ca}^{2+}\right]_{i}$ variations were esti- mated as changes in fluorescence signals over the baseline $(\Delta \mathrm{F} / \mathrm{F})$ after drug applications. In all recordings, background fluorescence measured in an ROI drawn in the darkest area of the field of view was extracted to every ROIs for each wavelength and for each image. Absolute $\left[\mathrm{Ca}^{2+}\right]_{i}$ variations were estimated as changes in fluorescence signals over the baseline $(\Delta \mathrm{F} / \mathrm{F})$. Baseline was established for each ROI as the average fluorescence over all pictures. Bleaching was corrected using a linear regression on the overall $\Delta \mathrm{F} / \mathrm{F}$ trace for each OXT neurons, which values were then subtracted to the $\Delta \mathrm{F} / \mathrm{F}$. Upon extraction of data, calculations, and corrections of $\Delta \mathrm{F} / \mathrm{F}$ for each neuron, the area under the curve (AUC) was calculated over a time period of $5 \mathrm{~min}$ before and after drug application. NPS ( $2 \mu \mathrm{M}$, Bachem) and SHA-68 (NPSR antagonist, $100 \mu \mathrm{M}$, Tocris Bioscience) were bath-applied during $20 \mathrm{~s}$ and $>15 \mathrm{~min}$, respectively. An OXT neuron was considered as being responsive to the drug, when the peak $\Delta \mathrm{F} / \mathrm{F}$ and the relative ratio of AUCs after drug application over baseline were both 4 SD and 20\% greater than in baseline conditions, respectively. The relative AUCs ratios values were used for quantitative analysis and called "relative AUC increase." Maximal peak reached after drug application was also measured and used in quantitative analysis. Data were averaged across OXT neurons per slices, which were used as the statistical unit over a minimum of 3 animals per condition. Image) software was also used on GCaMP6s pictures to produce illustrative pictures, such as the one in Figure 3. All $\mathrm{Ca}^{2+}$ imaging experiments were conducted at controlled room temperature of $22^{\circ} \mathrm{C}$.

Monitoring of intra-PVN release of OXT. A U-shaped microdialysis probe (Neumann et al., 1993; Torner et al., 2017) was implanted into the right PVN, and a guide cannula $(21 \mathrm{G}, 12 \mathrm{~mm})$ was stereotaxically placed $2 \mathrm{~mm}$ above the lateral ventricle. Two days later, the microdialysis probe was connected to a syringe mounted onto a microinfusion pump via polyethylene tubing and perfused with sterile Ringer's solution $(3.3 \mu \mathrm{l} /$ min) starting at 0800 for $2 \mathrm{~h}$ before the start of the experiment to establish an equilibrium between inside and outside of the microdialysis membrane. Then, five consecutive 30-min dialysates were collected: Samples 1 and 2 were taken under basal conditions, and Samples 3, 4, and 5 after i.c.v. infusion of either NPS ( 1 or $5 \mathrm{nmol} / 5 \mu \mathrm{l}$ ) or sterile Ringer's solution (vehicle, Veh, $5 \mu \mathrm{l}$ ). The outflow of the microdialysis probe was equipped with a tube holder that allowed direct sample collection into a $1.5-\mathrm{ml}$ Eppendorf tube containing $10 \mu \mathrm{l}$ of $0.1 \mathrm{M} \mathrm{HCl}$. Following this, samples were immediately frozen on dry ice and subsequently stored at $-20^{\circ} \mathrm{C}$ until quantification of OXT. OXT content was measured in evaporated dialysates by a highly sensitive and selective radioimmunoassay (de Jong et al., 2015).

Pharmacological inhibition of OXT receptor (OXTR). Guide cannulas were implanted above the lateral ventricle for i.c.v. infusion or above the left and right PVN for intra-PVN infusions. For evaluation of the local effect of the OXT receptor antagonist (OXTR-A; des-Gly$\mathrm{NH}_{2}, \mathrm{~d}\left(\mathrm{CH}_{2}\right)_{5}\left[\mathrm{Tyr}(\mathrm{Me})^{2}, \mathrm{Thr}^{4}\right] \mathrm{OVT}$ ) (Manning et al., 2012) on NPSinduced anxiolysis, four groups of conscious rats were studied, which received Veh/Veh, Veh/NPS, OXTR-A/Veh, or OXTR-A/NPS with a 5 -min interval. The infused dose of the OXTR-A ( $0.75 \mu \mathrm{g} / 5 \mu$ l i.c.v., 0.15 $\mu \mathrm{g} / 0.5 \mu \mathrm{l}$ intra-PVN) was selected on the basis of earlier experiments (Lukas et al., 2013). NPS was infused either i.c.v. ( $1 \mathrm{nmol} / 5 \mu \mathrm{l})$ or intraPVN $(0.2 \mathrm{nmol} / 0.5 \mu \mathrm{l})$; controls were infused with an equal volume of sterile Ringer's solution. Anxiety was tested using the light/dark box (LDB) 15 min after last intracerebral infusion. Two days later, the same rats were tested in the open field (OF) 15 min after they received a randomized treatment.

Chemogenetic silencing of PVN-OXT neurons. AAV ${ }_{1 / 2}$ OXTpr-hM4Di: mCherry was bilaterally microinfused into the left and right PVN, an i.c.v. guide cannula was implanted, and then the rats were single-housed to recover for $48 \mathrm{~h}$. On day 16 after AAV infusion, animals were housed singly in observation cages. On day 21 after AAV infusion and induction of expression of DREADD in OXT neurons, hM4Di, the $\mathrm{G}_{\mathrm{i}}$-coupled designer receptor, was activated by intraperitoneal injection of clozapine $\mathrm{N}$-oxide (CNO, $2 \mathrm{mg} / \mathrm{kg}$ ); controls received $1 \mathrm{ml} / \mathrm{kg}$ of sterile PBS. NPS (1 $\mathrm{nmol})$ or Veh $(5 \mu \mathrm{l})$ was infused i.c.v. $40 \mathrm{~min}$ later, i.e., $15 \mathrm{~min}$ before testing on the elevated plus maze (EPM). Expression of OXTpr-hM4Di: mCherry was verified in perfused, $40-\mu \mathrm{m}$ thick coronal brain slices by immunofluorescent staining of mCherry (1:1.000, Abcam, ab167453) 

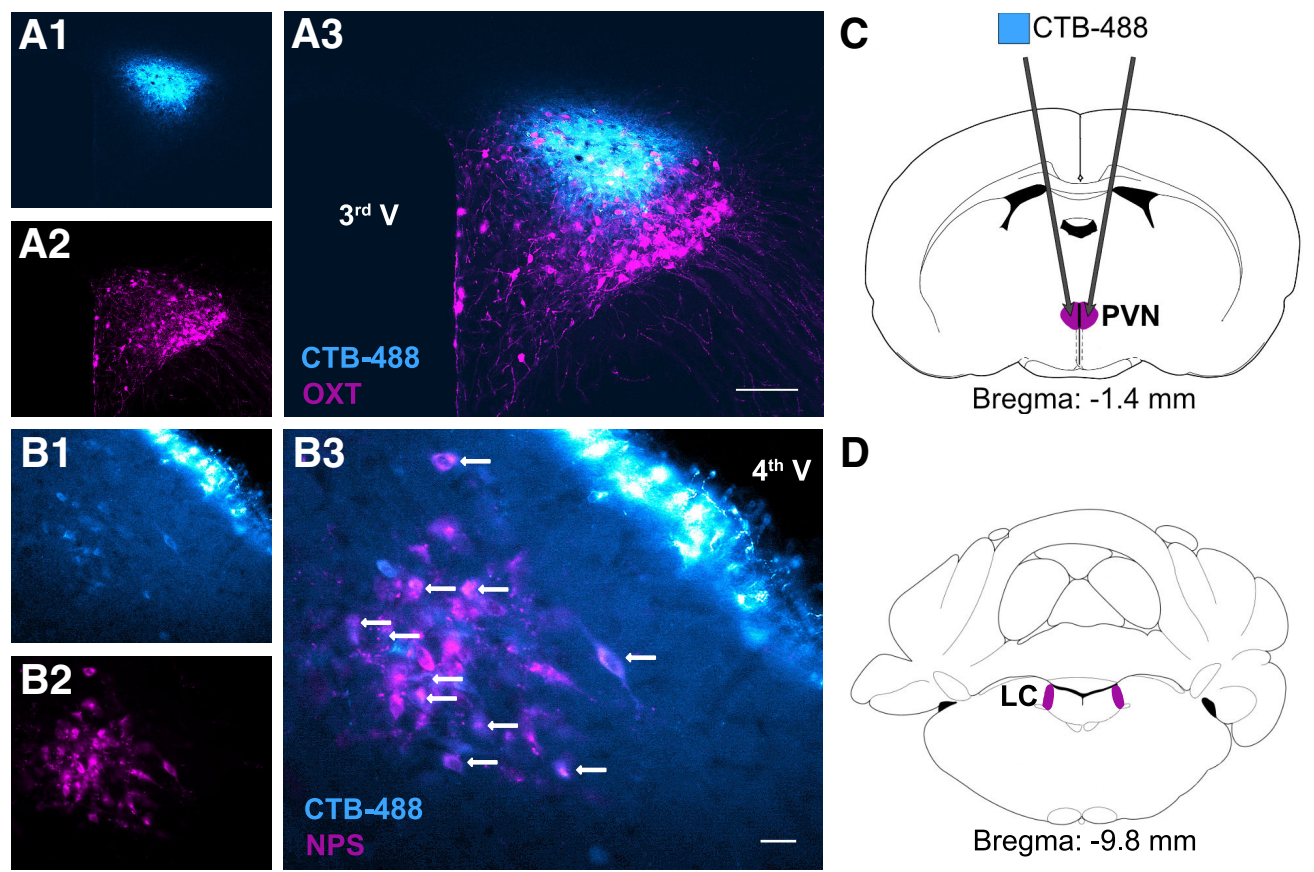

Figure 1. NPS neurons within the $L C$ innervate the hypothalamic PVN, a brain region that harbors OXT neurons. $\boldsymbol{A}, \mathrm{PVN}$ with OXT-immunoreactive neurons (magenta, $\boldsymbol{A}$ ) and infusion site of cholera toxin subunit B conjugated to AlexaFluor-488 (CTB-488, blue; A1). B, Five days following intra-PVN infusion of the tracer, retrogradely transported (TB-488 labeled neurons immunoreactive for NPS (magenta) in the LC (white arrows). $3^{\text {rd }} \mathrm{V}$, Third ventricle; $4^{\text {th }}$ V, fourth ventricle. Scale bars: $A 3,100 \mu \mathrm{m} ; \boldsymbol{B} 3,30 \mu \mathrm{m}$. C, Schematic drawing of intra-PVN infusion site of CTB-488. $\boldsymbol{D}$, LC harboring NPS-immunoreactive neurons.

and OXT (1:500) (Ben-Barak et al., 1985) and visualized using a DM5000B microscope (Leica). As an additional control, and to exclude potential effects of $\mathrm{CNO}$ and its metabolite clozapine on general anxietyrelated behavior (Gomez et al., 2017), sham-operated DREADD-free rats were treated with PBS or CNO $(2 \mathrm{mg} / \mathrm{kg}$, i.p.) before testing on the EPM.

Drug infusion procedure in conscious rats. For acute i.c.v. or intra-PVN infusions, the dummy cannula was replaced by the infusion cannula (25G, 14.7 mm i.c.v.; 27G, 14 mm intra-PVN). Sterile Ringer's solution was infused as vehicle control. After each infusion, the cannula was kept in place for $10 \mathrm{~s}$ to allow local substance diffusion. None of the druginfused rats showed any signs of tremor, convulsions, or wet-dog shakes in their homecage.

Behavioral testing. Anxiety-related behavior as well as locomotor activity were assessed using LDB, OF, or EPM during a 5-min test session 15 min after the last intracerebral infusion.

Briefly, the LDB consisted of a lit $(40 \times 50 \mathrm{~cm}, 100$ lux $)$ and a dark $(40 \times 30 \mathrm{~cm}, 0$ lux $)$ compartment connected via a small opening $(7.5 \times$ $7.5 \mathrm{~cm}$ ) enabling transition between the two floors. Rats were placed into the lit compartment, and the time spent in the light box was taken as measurement for anxiety-related behavior. LDB behaviors were assessed on video recordings using an automated video tracking system (EthoVision X7, Noldus).

For the OF, rats were placed in the center of the $\mathrm{OF}(80 \times 80 \times 40 \mathrm{~cm}$, 140 lux) and allowed to freely explore the arena while the time the animals spent in the center zone $(40 \times 40 \mathrm{~cm})$, the number of center zone entries and locomotor activity were monitored. OF behaviors were assessed on video recordings using an automated video tracking system (EthoVision X7, Noldus).

For testing on the EPM, rats were placed onto the neutral zone $(10 \times$ $10 \mathrm{~cm}$ ) facing a closed arm of the plus-shaped maze, which was elevated $(70 \mathrm{~cm})$ from the floor and consisted of two closed arms $(50 \times 10 \mathrm{~cm}, 10$ lux) and two open arms $(50 \times 10 \mathrm{~cm}, 40-50 \mathrm{lux})$. An observer blind to treatment determined the percentage of time the rats spent on the open arms as an indicator of anxiety-related behavior as well as the number of closed arm entries as an indicator of locomotor activity on a video recording.
Statistics. Statistical analyses were performed using SigmaPlot 11 (Systat). Two-tailed $t$ test was used to evaluate FACS analysis and anxietyrelated behavior in $\mathrm{CNO}$-only DREADD-free rats. For calcium imaging, data are expressed as mean \pm SEM. The Student's $t$ test was used to compare the size of the NPS-induced response after verification of the normality. Differences were considered significant for $p<0.05$. OXT content in microdialysates was analyzed using two-way ANOVA for repeated measures (time $\times$ treatment). In experiments designed out of four groups, anxiety-related behavior was analyzed using two-way ANOVA (first infusion $\times$ second infusion). In case of significant main or interaction effects $(p<0.05)$, Tukey-corrected post hoc comparisons were performed. Statistical outliers were calculated using the following formulas: Upper limit $=$ mean $+2 \times$ standard deviation; Lower limit $=$ mean $-2 \times$ standard deviation. In case a value exceeded or fell below the upper or lower limit, respectively, the experimental animal was not included in the statistics. Statistical outliers were calculated using the following formulas: Upper limit $=$ mean $+2 \times$ standard deviation; Lower limit $=$ mean $-2 \times$ standard deviation. In case a value exceeded or fell below the upper or lower limit, respectively, the experimental animal was not included in the statistics.

\section{Results}

\section{NPS afferents project toward the PVN that harbors} NPSR-expressing OXT neurons

To test for NPS neurons innervating the PVN, we infused the retrograde tracer CTB-488 bilaterally into the PVN. Five days later, dense labeling of NPS-immunoreactive neurons was detected throughout the LC, indicating prominent LC-NPS afferents to the PVN (Fig. 1). As NPSR expression has been described in the rat PVN (Xu et al., 2007), we specifically investigated NPSR expression in PVN-OXT neurons of male Wistar rats. In the absence of a specific NPSR antibody (Slattery et al., 2015), we performed FACS analysis in extracted PVN samples 3 weeks after bilateral intra-PVN infusion of a cell type-specific rAAV expressing Venus selectively under the control of an OXT promoter fragment 


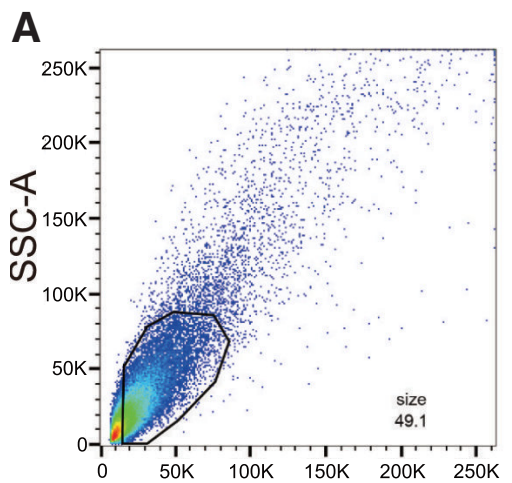

B FSC-A

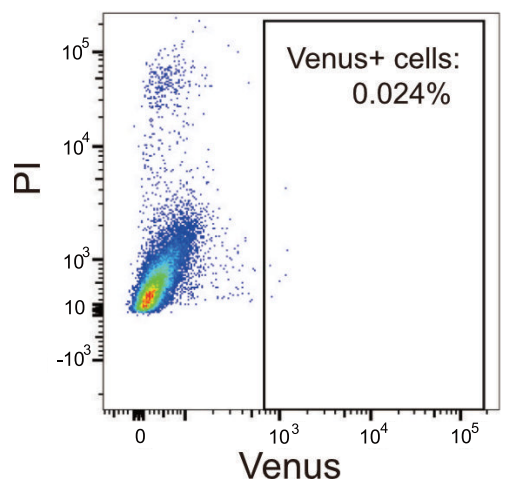

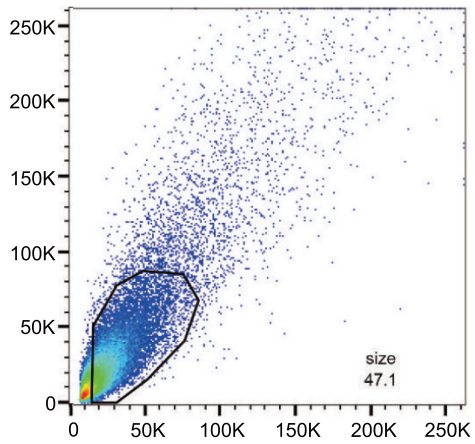

FSC-A

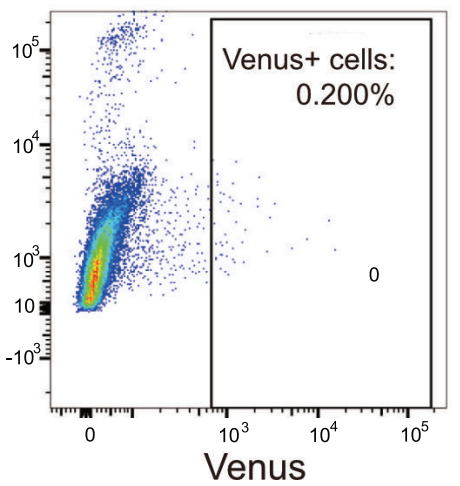

C
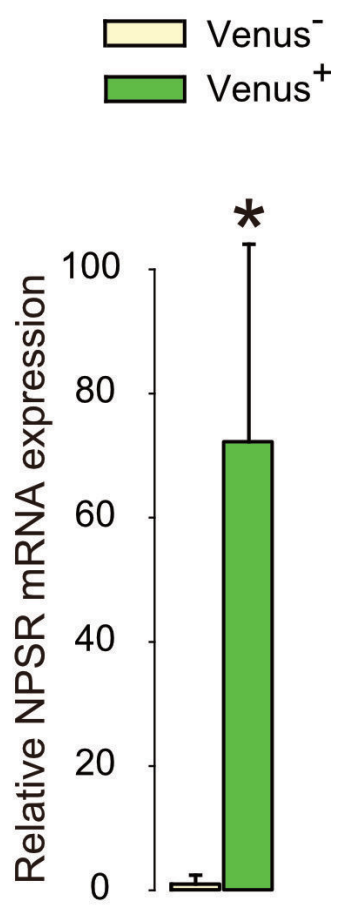

Figure 2. OXT neurons within the hypothalamic PVN and SON express NPSR mRNA. FACS plots indicate that cells were sorted by ( $\boldsymbol{A}$ ) size via side- (SSC) and forward-scattered light (FSC) and ( $\boldsymbol{B}$ ) fluorescence intensity in living cells negative for propidium iodide (PI). C, qRT-PCR of reversely transcribed RNA isolated from sorted viable cells demonstrated prominent NPSR mRNA expression in Venus ${ }^{+}$neurons, whereas NPSR mRNA expression in Venus ${ }^{-}$cells was almost negligible. Data are mean + SEM. ${ }^{*} p<0.05$.

$\left(\mathrm{AAV}_{1 / 2}\right.$ OXTpr-Venus). Hence, Venus expression was confined to PVN-OXT neurons (Knobloch et al., 2012). FACS analysis of viable cells in combination with qRT-PCR revealed that NPSR mRNA was predominantly expressed in Venus ${ }^{+}$ neurons, whereas NPSR expression in Venus ${ }^{-}$cells was almost negligible (Fig. 2).

\section{NPS activates OXT neurons within the PVN}

To study whether NPS activates OXT neurons, we used ultrasensitive fluorescent proteins (GCaMP6s) for imaging intracellular $\mathrm{Ca}^{2+}$ levels, which is based on rapid deprotonation of GFP following conformational change of calmodulin upon $\mathrm{Ca}^{2+}$ binding (Chen et al., 2013). Three weeks following bilateral infusion of AAV ${ }_{1 / 2} \mathrm{OXTpr-GCaMP6s}$ into the PVN, GCaMP6s was selectively expressed under the control of the OXT promoter fragment (Fig. 3A). Following hypothalamic slice preparation, part of OXT neurons were identified as constitutively active (113 of 372 neurons, $30.4 \%$ ), whereas the majority of neurons (259 of 372 neurons, $69.6 \%$ ) displayed low variability with respect to intracellular $\mathrm{Ca}^{2+}$ fluctuations and, thereby, were characterized as constitutively silent (Fig. 3B). While a subpopulation of silent OXT neurons ( 24 of $235,10.1 \%$ ) responded to NPS ( $2 \mu \mathrm{M}$ for $20 \mathrm{~s})$ by increased fluorescence indicative for transient rise in intracellular $\mathrm{Ca}^{2+}$ levels (AUC increase of $58.22 \pm 16.20 \%$, max $\Delta \mathrm{F} / \mathrm{F}_{0}$ of $75.02 \pm 22.03 \%$, duration of the response $16.63 \pm$ $6.40 \mathrm{~s}$; Fig. $3 C, D)$, no response to NPS was observed in the active OXT neurons ( 2 of $135,1,4 \%)$. In the presence of a selective NPSR antagonist (SHA-68, $100 \mu \mathrm{M}, 30 \mathrm{~min}$ ), NPS failed to induce any cellular response compared with baseline (AUC increase of $-3.53 \pm 3.25 \%, p<0.01 ; \max \Delta \mathrm{F} / \mathrm{F}_{0}$ of $16.63 \pm 3.55 \%$, $p<0.05$; Fig. $3 C, D$ ), indicating that the NPS-induced increase in intracellular $\mathrm{Ca}^{2+}$ in OXT neurons is specifically mediated via the NPSR.

Another indicator for a stimulated activity of OXT neurons is increased somatodendritic OXT release (Landgraf and Neumann, 2004). Thus, we monitored OXT release within the PVN of conscious rats in response to NPS ( 1 or 5 nmol, i.c.v.) using intracerebral microdialysis. Two-way ANOVA revealed an alteration in local OXT release in response to $\operatorname{NPS}\left(F_{(8,79)}=5.93, p<\right.$ $0.001)$. In detail, NPS dose-dependently evoked a significant rise in local OXT release during the first ( $5 \mathrm{nmol}, p<0.001$ vs Veh) and during the second and third ( 1 nmol, $p<0.05$ vs Veh) 30-min dialysis period, respectively, following NPS (Fig. 4).

\section{Selective inhibition of OXTR and chemogenetic silencing of} OXT neurons within the PVN prevent NPS-induced anxiolysis

To examine the behavioral relevance of NPS-evoked activation of OXT neurons, two strategies were used: First, OXTR were pharmacologically blocked by i.c.v. or intra-PVN infusion of a specific OXTR-A (des-Gly- $\mathrm{NH}_{2}, \mathrm{~d}\left(\mathrm{CH}_{2}\right)_{5}\left[\mathrm{Tyr}(\mathrm{Me})^{2}, \mathrm{Thr}^{4}\right.$ ]OVT) before i.c.v. or local infusion of NPS and behavioral testing on the LDB and in the OF, respectively, to assess anxiety-related behavior. Next, PVN-OXT neurons were chemogenetically silenced before i.c.v. infusion of NPS and behavioral testing on the EPM.

\section{Pharmacological blockade of OXTR by OXTR-A}

Pharmacological blockade of OXTR signaling by preinfusion of a selective OXTR-A 5 min before NPS infusion at least partially prevented NPS-induced anxiolysis in the LDB (Fig. 5). Specifically, comparison of the four existing groups (Veh/Veh, Veh/ 
A
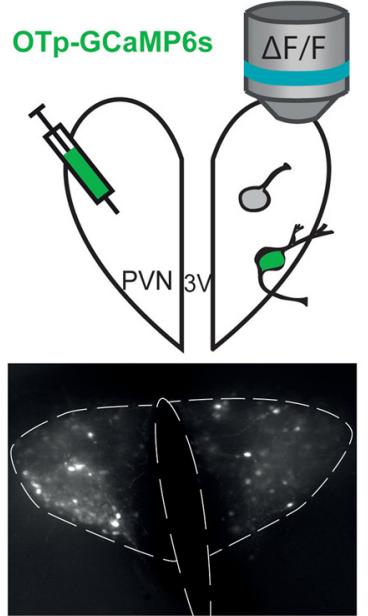

B
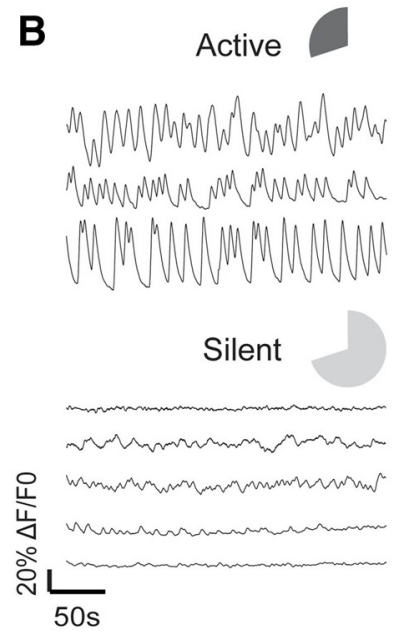

C
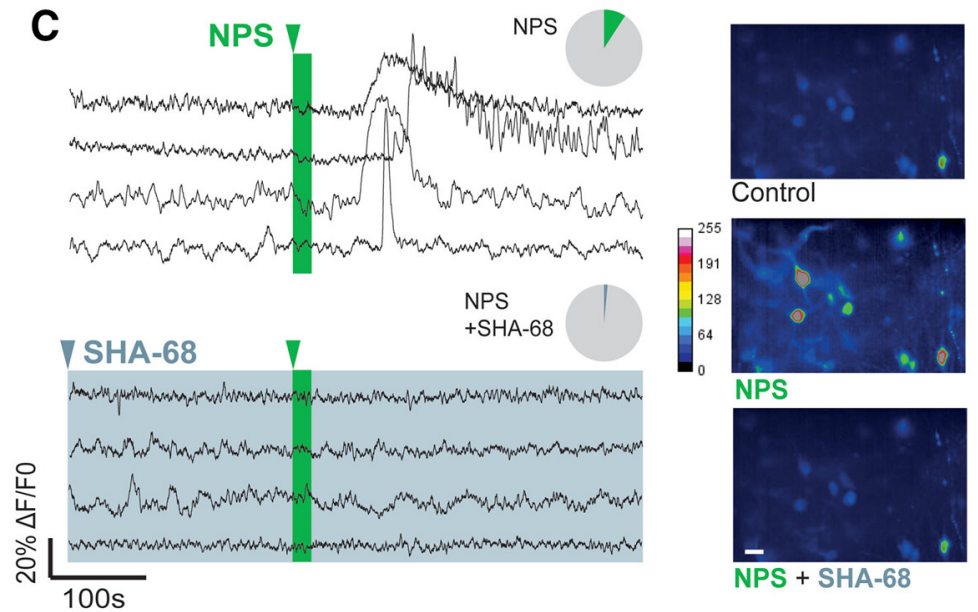

NPS

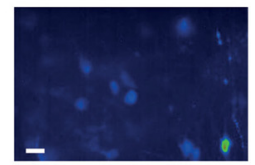

NPS + SHA 68

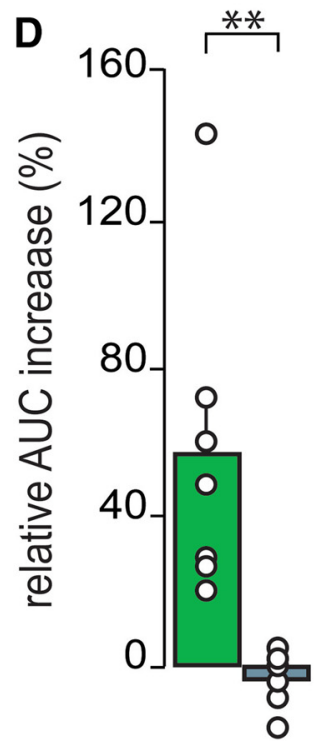

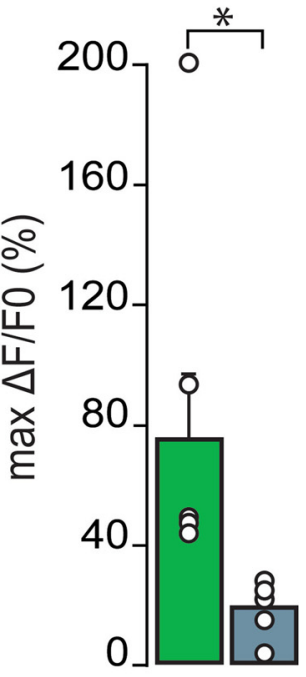

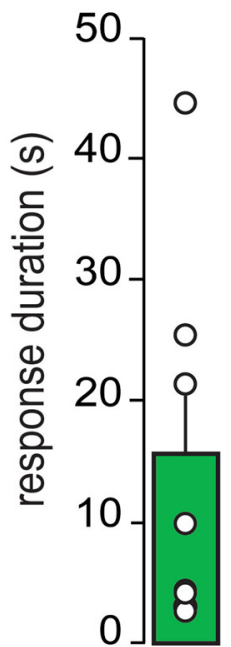

Figure 3. NPS effects on PVN-OXT neurons in hypothalamic slice preparation $(\boldsymbol{A}-\boldsymbol{D}) . \boldsymbol{A}$, Schematic drawing of the PVN OXTprGCaMPGs virus infusion and subsequent $\left[\mathrm{Ca}^{2+}\right]_{i}$ imaging of OXT neurons. $B$, Basal activity of two distinct subpopulations of OXT neurons (dark gray represents active; light gray represents silent) illustrated by typical $\Delta \mathrm{F} / \mathrm{F} 0$ traces. Pie charts represent the proportion of active (up) and silent (down) OXT neurons: $n$ slices $\left(n_{s}\right)=11, n$ OXT neurons $\left(n_{n}\right)=237$. C, Pie charts of the proportion of responsive OXT neurons to NPS application alone ( $2 \mu \mathrm{m}, 20 \mathrm{~s} ; n_{\mathrm{s}}=11, n_{\mathrm{n}}=24$ of 237 ; green) or in the presence of NPSR antagonist (SHA-68 $100 \mu \mathrm{m},>15 \mathrm{~min} ; n_{\mathrm{s}}=6, n_{\mathrm{n}}=3$ of 135; light blue) and typical $\Delta \mathrm{F} / \mathrm{FO}$ traces. Pseudo-color video extract of identified OXT neurons through GCaMP6s imaging $\left[\mathrm{Ca}^{2+}\right]_{i}$ in control conditions (gray), in the presence of NPS (green) or NPS + SHA-68 (light blue) (stacks of 50 images/10 s of recording). Scale bar, $20 \mu \mathrm{m}$. D, Relative AUC increase and maximal $\Delta \mathrm{F} / \mathrm{FO}$

NPS, OXTR-A/Veh, OXTR-A/NPS) revealed that, in Veh-preinfused rats, i.c.v. postinfusion of NPS increased the percentage of time the rats spent in the lit compartment of the $\operatorname{LDB}\left(F_{(1,31)}=3.06\right.$, $p=0.091$; factor postinfusion: $F_{(1,31)}=$ $4.33, p=0.047 ; \mathrm{Veh} / \mathrm{NPS}$ vs Veh/Veh: $p=$ 0.012 ). Preinfusion with the OXTR-A prevented the anxiolytic effect of NPS, although no significant difference was found between OXTR-A/NPS and Veh/ NPS groups $(p=0.084)$. The OXTR-A alone did not affect anxiety-related behavior (OXTR-A/Veh vs. Veh/Veh: $p=0.50$ ). Neither NPS nor OXTR-A, alone or in combination, influenced the locomotor activity in the LDB indicated by traveled distance (interaction: $F_{(1,31)}=0.09, p=$ 0.77).

In the $\mathrm{OF}$, a similar result was found (Fig. 5). Although the mean time in the center was two-fold greater in icv Vehpreinfused/NPS-postinfused rats compared with Veh/Veh rats, this difference was only a statistical trend and did not reach significance (interaction: $F_{(1,33)}=$ 2.42, $p=0.13$; postinfusion: $F_{(1,33)}=$ $3.75, p=0.06)$. Again, none of the treatments changed locomotor activity in the $\mathrm{OF}$ as reflected by the traveled distance (interaction: $F_{(1,33)}=0.08, p=0.79$ ).

To localize the effects of OXTR-A pretreatment and NPS within the PVN, local infusions were performed (Fig. 5). In the LDB (interaction: $F_{(1,40)}=1.81, p=$ 0.19 ; postinfusion: $F_{(1,40)}=5.84, p=$ 0.021 ), local NPS exerted a robust anxiolytic effect in Veh-pretreated rats (Veh/ NPS versus Veh/Veh: $p=0.006$ ). However, preinfusion of the OXTR-A prevented this anxiolytic effect of NPS, although no significant difference was found between OXTR-A/NPS and Veh/ NPS groups $(p=0.089)$. The OXTR-A alone did not affect anxiety-related behavior (OXTR-A/Veh versus Veh/Veh: $p=$ 0.88). Neither local OXTR-A nor NPS, alone or in combination, changed the locomotor activity indicated by the distance traveled in the LDB $\left(F_{(1,30)}=0.17, p=\right.$ $0.68)$.

In the OF, intra-PVN infusion of NPS almost doubled the mean time in the center in Veh-preinfused rats compared to

\section{$\leftarrow$}

of OXT neurons in the presence of NPS $\left(n_{\mathrm{s}}=11\right.$; green) or $\mathrm{NPS}+\mathrm{SHA}-68\left(n_{s}=6\right.$, light blue). Only response duration of OXT neurons in the presence of NPS $\left(n_{s}=11\right.$; green) are represented here. White circles represent the average value per slice. ${ }^{*} p<0.05$ (Student's $t$ test). ${ }^{* *} p<0.01$ (Student's $t$ test). 


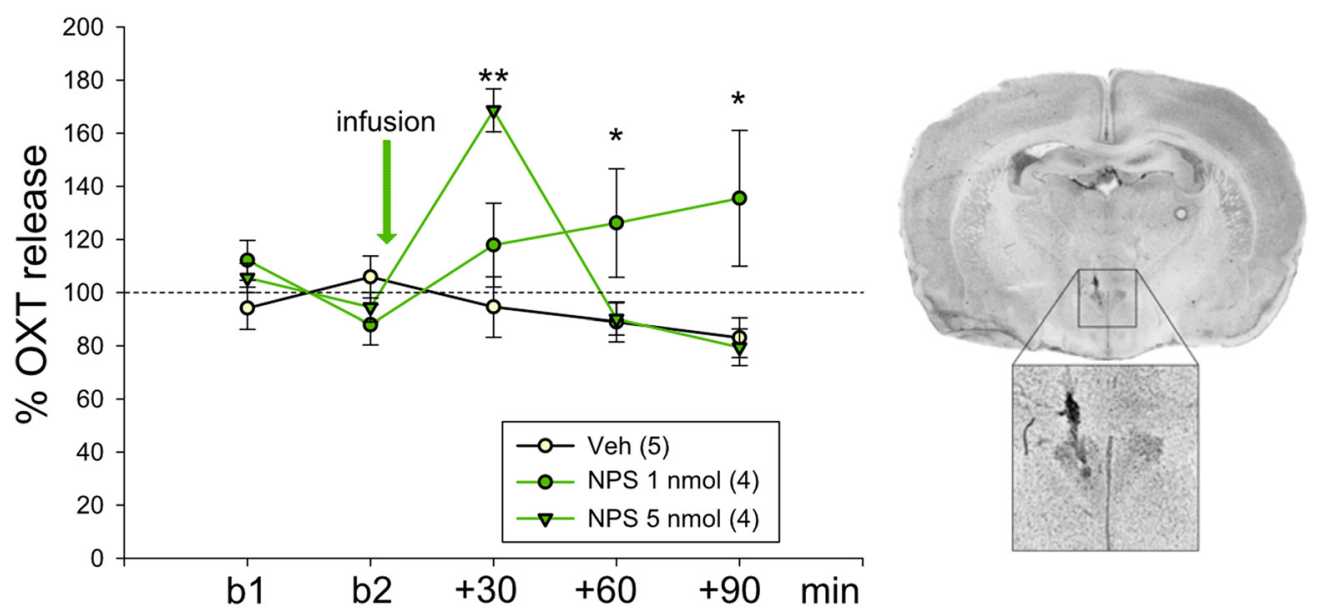

Figure 4. NPS effects on intracerebral OXT release in the PVN of conscious male rats. OXT content in 30-min microdialysates sampled within the PVN under basal conditions (b1 and b2), and after i.c.v. infusion of either Veh or NPS ( 1 or $5 \mathrm{nmol})$, as well as a representative microphotograph of a Nissl-stained coronal section demonstrating the placement of the microdialysis probe within the PVN. Data are expressed as percentage of baseline (mean of basal 1 and $2 ;=100 \%$; dotted line) \pm SEM. Numbers in parentheses indicate group size. ${ }^{* *} p<0.01$ vs. all; ${ }^{*} p<0.05$ versus respective Veh.
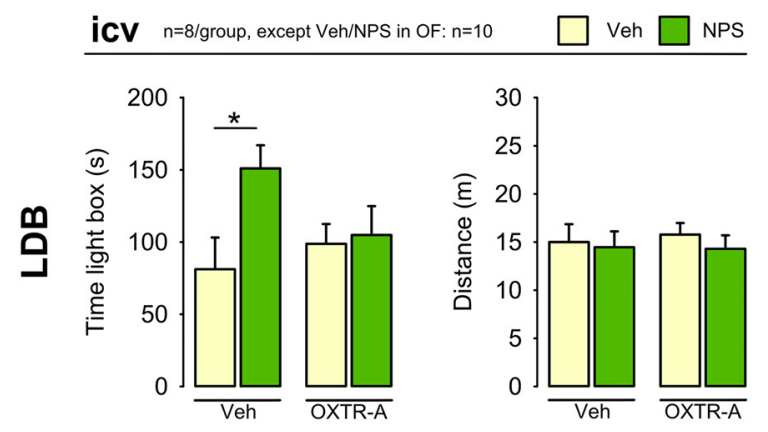

$\underline{\text { PVN LDB: Veh/Neh (13), Veh/NPS (11), OXTR-ANeh (8), OXTR-A/NPS (9) }}$
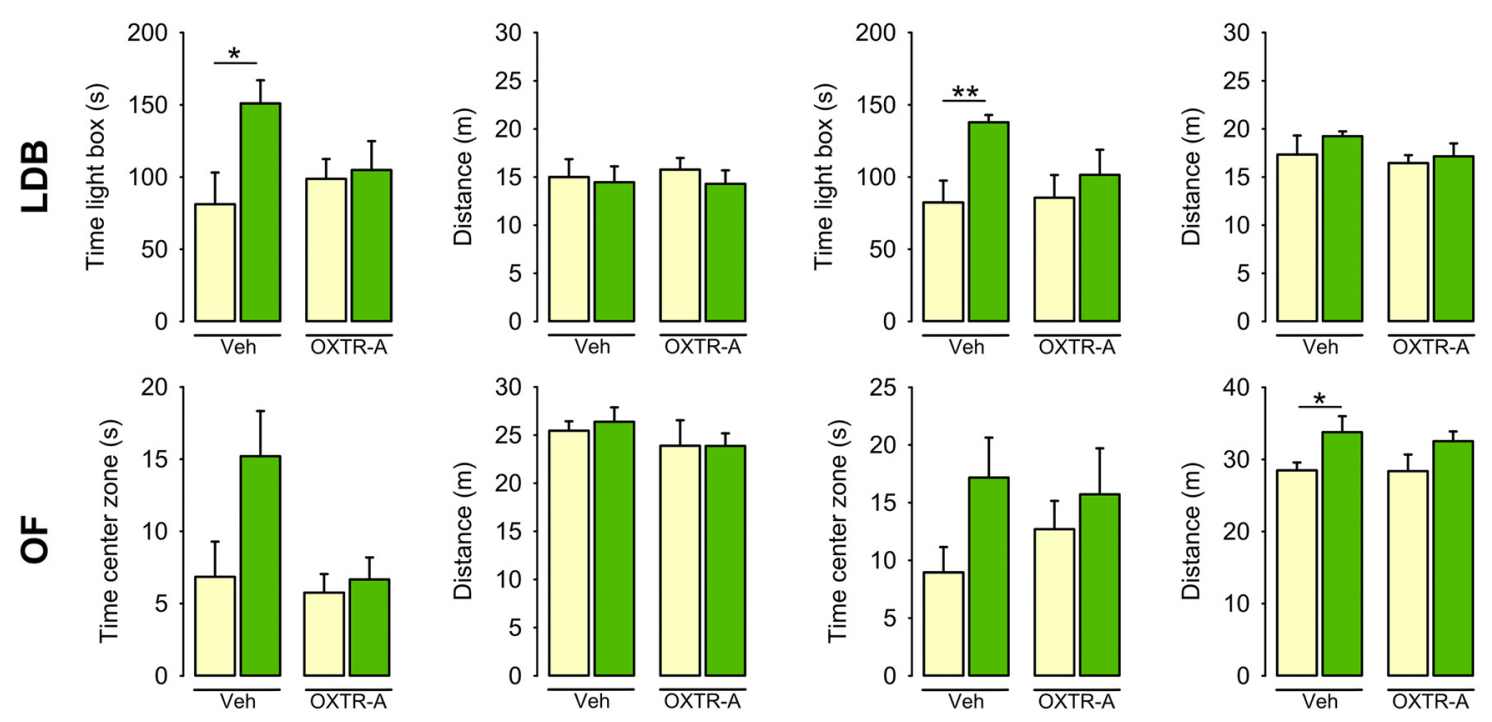

Figure 5. Intracerebroventricular and intra-PVN preinfusion with an OXTR antagonist blocked NPS-induced anxiolysis. Male rats were infused with a selective $0 X T R$ antagonist $(0 X T R-A, 0.75 \mu g$ i.c.v.; $0.15 \mu \mathrm{g}$ intra-PVN) before infusion with either NPS (...) ( $1 \mathrm{nmol}$ i.c.v.; $0.2 \mathrm{nmol}$ intra-PVN) or Veh. The time spent in the lit compartment of the LDB (upper row) and the time spent in the center zone of the $\mathrm{OF}$ (lower row) indicate anxiety-related behavior. Traveled distance indicates locomotor activity in the lit and dark compartment of the LDB, and center and outer OF zones of the $0 \mathrm{~F}$, respectively. Data are mean + SEM. Group sizes icv: $n=8-10$; intra-PVN: $n=8-13$ as indicated above graph; ${ }^{*} p<0.05,{ }^{* *} p<0.01$ versus Veh.

Veh/Veh rats; however, this effect, which was prevented by preinfusion of the OXTR-A, was only a statistical trend and did not reach significance (interaction: $F_{(1,33)}=0.675, p=0.41$; postinfusion: $\left.F_{(1,33)}=3.16, p=0.08\right)$. Local NPS infusion increased locomotor activity as indicated by elevated traveled distance in Veh-pretreated rats (interaction: $F_{(1,33)}=0.09, p=0.75$; postinfusion: $F_{(1,33)}=6.98, p=0.012$; Veh/Veh versus Veh/NPS: $p=$ 0.013; Fig. 5).

\section{Chemogenetic silencing of PVN-OXT neurons}

Following intra-PVN infusion of $\mathrm{AAV}_{1 / 2}$ OXTpr-hM4Di: mCherry, an inhibitory DREADD was expressed under the control of the OXT promoter fragment. Quantitative analysis of the PVN showed that $93.0 \pm 1.4 \%$ of mCherryimmunopositive cells $(n=278)$ expressed OXT, and $94.2 \pm$
$1.2 \%$ of OXT-immunoreactive neurons $(n=274)$ expressed hM4Di:mCherry, revealing an efficient and specific virus expression. After intraperitoneal CNO (Fig. 6), i.c.v. NPS failed to induce anxiolysis suggesting DREADD-mediated inhibition of PVN-OXT neurons and their importance for NPS-induced anxiolysis. On the EPM, two-way ANOVA revealed a main effect of the first $\left(F_{(1,31)}=6.63, p=0.016, \mathrm{CNO}\right.$ vs PBS $)$ and second infusion $\left(F_{(1,31)}=7.65, p=0.010\right.$, NPS vs Veh). In detail, NPS increased the percentage of time spent on the open arms of the EPM in PBS-pretreated rats (PBS/NPS vs PBS/Veh: $p=0.008$ ) indicative of an anxiolytic effect, whereas $\mathrm{CNO}$ pretreatment prevented the effect of NPS (CNO/NPS vs PBS/NPS: $p=0.014$; $\mathrm{CNO} / \mathrm{Veh}$ vs CNO/NPS: $p=0.25$ ). Moreover, NPS increased the percentage of open arm entries (main effect of the first infusion: $F_{(1,35)}=11.60, p=0.002$; second infusion: $F_{(1,31)}=10.42, p=$ 
A

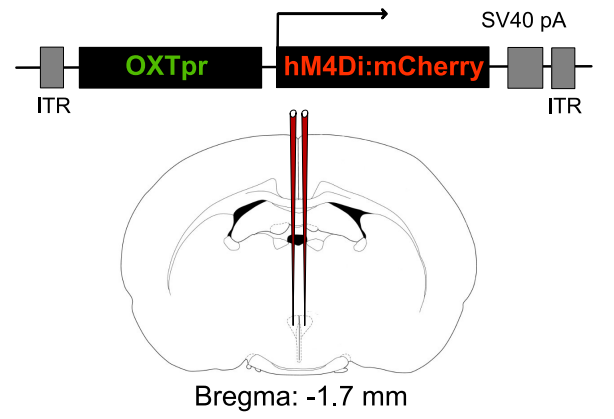

B

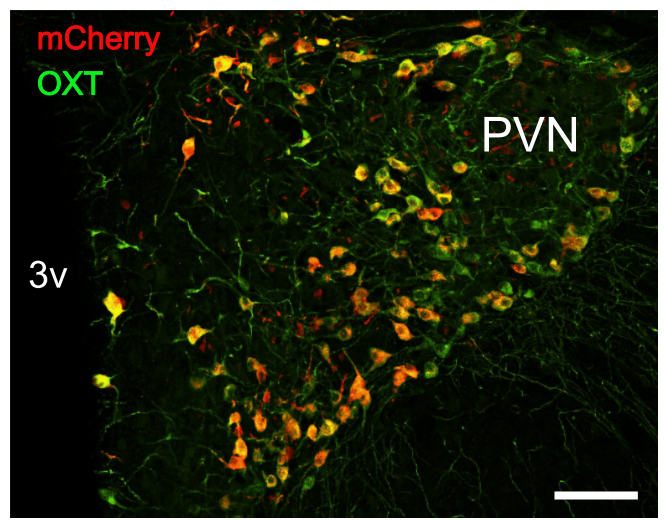

E

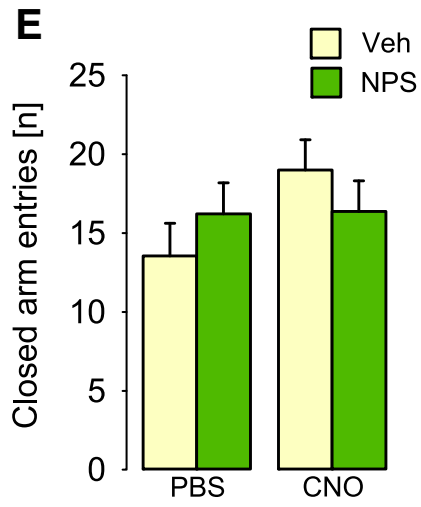

H

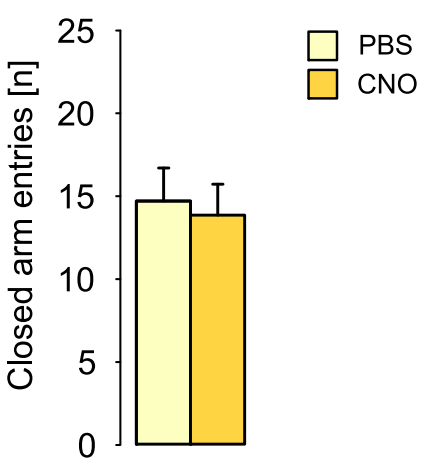

Figure 6. Chemogenetic silencing of PVN-OXT neurons prevented the anxiolytic effect of a subsequent NPS infusion. $A$, Schematic drawing of rAAV construct used to transfect PVN neurons. $\boldsymbol{B}$, Virally introduced expression of an inhibitory DREADD (hM4Di:mCherry) in OXT neurons within the PVN. Scale bar, $100 \mu \mathrm{m}$. 3v, Third ventricle. To evaluate the effect of chemogenetic silencing of PVN-OXT neurons on NPS-induced anxiolysis $(\boldsymbol{C}-\boldsymbol{E})$, rats were pretreated with either PBS or CNO ( $2 \mathrm{mg} / \mathrm{kg}$; i.p.), followed by i.c.v. infusion of either Ringer's solution (Veh, $5 \mu$ l) or NPS (1 nmol); group sizes: $n=8$ or 9 , except CN0/Veh: $n=6$. To analyze potential effects of CN0 or its metabolites on anxiety-related behavior, sham-operated DREADD-free rats were injected with either PBS or CNO (2 mg/kg; i.p.); group sizes: $n=7 . \boldsymbol{C}, \boldsymbol{F}$, Percentage of time spent on the open arms of the EPM. $\boldsymbol{D}, \boldsymbol{G}$, Percentage of open arm entries. $\boldsymbol{E}, \boldsymbol{H}$, Number of closed arm entries reflects locomotor activity during the 5 -min test period. Data are mean + SEM. ${ }^{*} p<0.05$ versus all or as indicated. ${ }^{* *} p<0.01$ versus all or as indicated. ${ }^{\#} p<0.05$ versus all.

0.003; PBS/NPS vs PBS/Veh: $p=0.048)$, an effect that was also blocked by chemogenetic silencing (CNO/NPS vs PBS/NPS: $p=$ 0.042; CNO/Veh vs CNO/NPS: $p=0.019)$. CNO alone resulted in a partial increase in anxiety-related behavior as seen by a reduction in the percentage of open arm entries only $(p<0.05$ vs all). None of the drugs altered locomotor activity expressed by the number of closed arm entries $\left(F_{(1,31)}=1.69, p=0.21\right)$. Control intraperitoneal application of CNO alone to sham-operated animals revealed no behavioral effects during 5-min testing on the EPM, as the percentage of time spent on the open arms $\left(t_{(12)}=\right.$ $0.33, p=0.75)$, the percentage of open arm entries $\left(t_{(12)}=-0.71\right.$, $p=0.49)$, and the number of closed arm entries $\left(t_{(12)}=0.31, p=\right.$ 0.76) did not differ in comparison with PBS-treated rats.

\section{Discussion}

The present study describes a novel intrahypothalamic mechanism with NPS activating a subpopulation of OXT neurons within the PVN that mediate the anxiolytic effect of NPS. This finding comes at a time of growing interest in brain neuropeptides as potential therapeutic targets to treat psychopathologies, such as anxiety disorders (Pape et al., 2010; Neumann and Landgraf, 2012; Neumann and Slattery, 2016); and both OXT and NPS have been established as potent anxiolytic neuropeptides of the brain (Xu et al., 2004; Neumann, 2008; Pape et al., 2010; Neumann and Landgraf, 2012; Slattery et al., 2015; van den Burg et al., 2015; Neumann and Slattery, 2016). Herein, our findings demonstrate pericoerulear NPS 
fibers innervating the PVN and NPSR expression in hypothalamic OXT neurons. Moreover, NPS activated a subpopulation of PVNOXT neurons as reflected by transient $\mathrm{Ca}^{2+}$ influx and increased the somatodendritic release of OXT in the PVN under otherwise basal conditions. Both pharmacological blockade of local OXTR as well as chemogenetic silencing of OXT neurons within the PVN blocked the NPS-induced anxiolysis demonstrating the essential involvement of OXT neurons within the PVN.

Whereas NPS projections in the rat brain have not been studied so far, NPS-immunopositive fibers originating within the LC have been detected in various mouse brain regions, including the PVN as shown in C57BL/6 mice (Clark et al., 2011). Here, we can confirm the existence of NPS neurons in the LC projecting toward the PVN also in the rat using a retrograde tracer. Thus, in both rats and mice, the PVN has been identified as a target site of NPS neurons in the brainstem. Specifically, preinfusion of a selective OXTR-A (Manning et al., 2012) into the cerebral ventricular system prevented the NPS-induced reduction in anxiety levels specifically seen in the LDB, whereas in the OF, the anxiolytic effect of NPS did not reach statistical significance.

Previous studies using in situ hybridization revealed abundant NPSR mRNA expression in the PVN of rats (Xu et al., 2007). In our study, we applied a sensitive and highly specific technique (FACS analysis of Venus-labeled PVN and SON OXT neurons) and demonstrated prominent NPSR expression in OXT neurons, whereas NPSR mRNA in Venus ${ }^{-}$cells, likely to be specifically vasopressin or corticotrophin-releasing hormone $(\mathrm{CRH})$ neurons, was almost negligible. Earlier experiments confirmed selective expression of Venus in OXT neurons with $>97 \%$ colocalization of OXT supporting the significance of our results in terms of cell-type-specific Venus labeling (Knobloch et al., 2012). In this context, it is worth mentioning that our intention to localize NPSR protein in OXT neurons of the PVN with NPSR antibodies used before (Leonard and Ring, 2011) failed, as subsequent analysis using NPSR knock-out mouse brains revealed a severe lack of specificity of these antibodies (Slattery et al., 2015).

Based on the finding of NPSR mRNA expression in OXT neurons of the PVN, we analyzed the neurophysiological effects of NPS on the activity of OXT neurons using ultrasensitive fluorescent proteins. In hypothalamic slice preparations, a subpopulation of constitutively silent OXT neurons expressing ultrasensitive fluorescent $\mathrm{Ca}^{2+}$ imaging marker GCaMP6s responded to synthetic NPS with transient $\mathrm{Ca}^{2+}$ influx, which reflects neuronal activation. The recorded $\mathrm{Ca}^{2+}$ response was heterogeneous, but massive, with a slow rise time and relative long-lasting responses of several seconds. This observation is compatible with a previous study in hippocampal mouse neurons (Erdmann et al., 2015). The NPS effects on intracellular $\mathrm{Ca}^{2+}$ also studied in NPSR1-transfected HEK293T and CHO cells are most likely mediated by NPSR-induced $\mathrm{G}_{\mathrm{q}}$ signaling (Reinscheid et al., 2005; Liao et al., 2016; Clark et al., 2017). In vivo, it has recently been demonstrated that NPS promotes anxiolysis in a phospholipase C-dependent manner and increases intracellular $\mathrm{Ca}^{2+}$ levels characterized by increased phosphorylation and synthesis of $\mathrm{Ca}^{2+} /$ calmodulin-dependent kinase II within the rat medial amygdala (Grund and Neumann, 2017).

It is important to note that repeated NPS application failed to induce a repeated $\mathrm{Ca}^{2+}$ response in the same OXT neurons, as already reported by previous studies (Jüngling et al., 2008; Meis et al., 2008). While the mechanism involved is yet to be determined, one can hypothesize desensitization of NPSR. However, the specific involvement of NPSR on NPS-induced activation of OXT neurons was successfully demonstrated, because NPS failed to increase intracellular $\mathrm{Ca}^{2+}$ levels in the presence of the selective NPSR antagonist SHA-68 (Okamura et al., 2008; Ruzza et al., 2010).

The presence of extracellular $\mathrm{Ca}^{2+}$ and the rise in intracellular $\mathrm{Ca}^{2+}$ were found to be essential for both OXT secretion from neurohypophysial terminals (Fisher and Bourque, 1996) as well as for somatodendritic release in the SON and PVN (Neumann et al., 1993; Lambert et al., 1994; Ludwig et al., 2002). To test whether NPS also affects the secretory activity of OXT neurons within the PVN, we used microdialysis in combination with a highly sensitive radioimmunoassay. Indeed, we could demonstrate that NPS dose-dependently stimulated OXT release within the PVN of conscious rats under otherwise basal conditions. Central NPS infusion at $1 \mathrm{nmol}$ induced a measurable and longlasting increase in OXT release from neuronal structures within the PVN over 60 min as reflected by an increased OXT content in the two consecutive post-treatment 30 -min microdialysates. In contrast, $5 \mathrm{nmol}$ of NPS induced a rather rapid increase in OXT release, which declined to baseline during the second sampling period after treatment. However, the underlying mechanisms of the dose-dependent effects of NPS on the dynamics of OXT release and the differential contribution of various $\mathrm{Ca}^{2+}$ sources are currently unknown.

The stimulatory effects of NPS on the activity of OXT neurons within the PVN, which are NPSR-mediated, highlight an intrahypothalamic mechanism at the cellular level. Moreover, we can show that NPS exerts a behavioral effect directly within the PVN, and this anxiolytic effect requires the activation of local OXT neurons. Based on pharmacological and chemogenetic inhibition of the OXT system, our results indicate an important role for OXT to mediate the anxiolytic effect of NPS in the hypothalamic PVN. Specifically, preinfusion of a selective OXTR-A (Manning et al., 2012) into the cerebral ventricular system was able to prevent the NPS-induced reduction in anxiety levels specifically seen in the LDB, whereas in the OF, the anxiolytic effect of NPS did not reach statistical significance. Infusion of the OXTR-A alone did not alter anxiety levels, which confirms earlier results in male rats under basal conditions (Waldherr and Neumann, 2007). Importantly, also local preinfusion of OXTR-A bilaterally into the PVN reduced the robust NPS-induced anxiolysis seen in rats preinfused with vehicle, although to a lower degree. Thus, we hypothesize that NPS infused into the PVN activates local OXT neurons resulting in local somatodendritic OXT release. Both endogenous as well synthetic OXT have been repeatedly shown to exert an anxiolytic effect within the PVN (Neumann et al., 2000; Blume et al., 2008; Jurek et al., 2012; van den Burg et al., 2015). Possible underlying mechanisms of local OXT-induced anxiolysis are likely to include inhibitory effects on local CRF neurons (Jurek et al., 2015). As OXT neurons are glutamatergic in nature, their activation might also increase synaptic glutamate release. This will comprise an autoexcitatory network structure synchronizing OXT release throughout the hypothalamus (Dabrowska et al., 2011; for review, see Johnson and Young, 2017). Moreover, local NPS may activate those OXT neurons in the PVN, which project to other brain regions, such as the amygdala (Knobloch et al., 2012), where OXT was also found to reduce anxiety- and fearrelated behavior (Bale et al., 2001; Viviani et al., 2011).

To specifically prove for the involvement of PVN-OXT neurons in the behavioral effects of NPS, we chemogenetically inhibited OXT neurons of the PVN using a $\mathrm{G}_{\mathrm{i}}$-coupled DREADD selectively expressed under the control of the OXT promoter fragment. At the cellular level, chemogenetic silencing using 
$\mathrm{AAV}_{1 / 2}$ OXTpr-hM4Di:mCherry has been shown to result in reduced mean frequency of spikes induced by application of currents, increased inward currents, and decreased input resistance of OXT neurons (Eliava et al., 2016). Thus, chemogenetically silenced OXT neurons can no longer be activated by NPS. In our experiment, DREADD-evoked silencing of OXT neurons reliably prevented the anxiolytic effect of a subsequent central NPS infusion, as seen on the EPM, which provides final evidence for the essential role of stimulated PVN-OXT neurons in mediating this behavioral effect of NPS. Importantly, injection of CNO to rats expressing DREADD in OXT neurons slightly increased anxietyrelated behavior, as seen from a reduced percentage of open arm entries on the EPM. Thus, chemogenetic silencing of OXT neurons might result in a general neuronal inhibition, including abolished intracerebral OXT release under basal conditions within the PVN or in other relevant limbic brain regions, important for the individual level of anxiety. Also, dysregulation of the $\mathrm{CRH}$ system after silencing of OXT neurons, especially during exposure to an emotional stressor, such as the EPM, cannot be ruled out, the more as OXT was found to attenuate the stressinduced expression of CRH in a CREB-dependent manner (Jurek et al., 2015).

Recently, it has been shown that the CNO metabolite clozapine, an atypical antipsychotic, potently activates DREADD (Gomez et al., 2017). To exclude unspecific behavioral effects of CNO or its metabolite clozapine demonstrated at doses $>5 \mathrm{mg} / \mathrm{kg}$ (i.p.) (MacLaren et al., 2016), we have applied CNO at a dose of $2 \mathrm{mg} / \mathrm{kg}$ (i.e., at subthreshold level) to specifically activate DREADD expressed by OXT neurons. Moreover, control application of CNO alone in DREADD-free Wistar rats did not alter anxiety-related behavior and locomotor activity on the EPM. Therefore, we are confident that stimulation of an inhibitory DREADD resulted in selective inhibition of OXT neurons, particularly because i.c.v. and local OXTR antagonism before NPS infusion leads to comparable effects on anxiety-related behavior.

Based on our results, we suggest the following scenario under physiological conditions: In response to a challenging and stressful situation, pericoerulear NPS neurons, which are CRHsensitive (Jüngling et al., 2012), become activated resulting in local NPS release as shown in the basolateral amygdala during forced swimming (Ebner et al., 2011). However, NPS neurons also project to the PVN as described in mice (Clark et al., 2011), and in rats using a retrograde tracer infused into the PVN (Fig. 1). Thus, NPS released within the PVN from NPS terminals activates OXT neurons, as indicated by increased intracellular $\mathrm{Ca}^{2+}$ levels, which results in local OXT release or stimulation of centrally projecting OXT neurons as described above. Finally, the rise in OXT availability in the regional extracellular fluid results in the modulation of an appropriate anxiety response of an individual to cope with the environmental challenge.

In conclusion, our findings demonstrate a novel intrahypothalamic mechanism involving NPSR-expressing OXT neurons of the PVN, which are activated by NPS and respond with transient increase in intracellular $\mathrm{Ca}^{2+}$ and local somatodendritic OXT release. The stimulation of local OXT neurons is essential for NPS-induced anxiolysis, as this effect was blocked by specific pharmacological and chemogenetic inhibition of the OXT system. These findings provide important evidence for interactions of NPS with another neuropeptidergic system but obviously warrant further research into how these circuits orchestrate specific physiological effects resulting in distinct behavioral outputs (e.g., the regulation of stress or anxiety-related behavior).

\section{References}

Anthony TE, Dee N, Bernard A, Lerchner W, Heintz N, Anderson DJ (2014) Control of stress-induced persistent anxiety by an extra-amygdala septohypothalamic circuit. Cell 156:522-536.

Bale TL, Davis AM, Auger AP, Dorsa DM, McCarthy MM (2001) CNS region-specific oxytocin receptor expression: importance in regulation of anxiety and sex behavior. J Neurosci 21:2546-2552.

Beck B, Fernette B, Stricker-Krongrad A (2005) Peptide S is a novel potent inhibitor of voluntary and fast-induced food intake in rats. Biochem Biophys Res Commun 332:859-865.

Beiderbeck DI, Lukas M, Neumann ID (2014) Anti-aggressive effects of neuropeptide $S$ independent of anxiolysis in male rats. Front Behav Neurosci 8:185.

Ben-Barak Y, Russell JT, Whitnall MH, Ozato K, Gainer H (1985) Neurophysin in the hypothalamo-neurohypophysial system: I. Production and characterization of monoclonal antibodies. J Neurosci 5:81-97.

Blume A, Bosch OJ, Miklos S, Torner L, Wales L, Waldherr M, Neumann ID (2008) Oxytocin reduces anxiety via ERK1/2 activation: local effect within the rat hypothalamic paraventricular nucleus. Eur J Neurosci 27:1947-1956.

Chen TW, Wardill TJ, Sun Y, Pulver SR, Renninger SL, Baohan A, Schreiter ER, Kerr RA, Orger MB, Jayaraman V, Looger LL, Svoboda K, Kim DS (2013) Ultrasensitive fluorescent proteins for imaging neuronal activity. Nature 499:295-300.

Clark SD, Duangdao DM, Schulz S, Zhang L, Liu X, Xu YL, Reinscheid RK (2011) Anatomical characterization of the neuropeptide S system in the mouse brain by in situ hybridization and immunohistochemistry. J Comp Neurol 519:1867-1893.

Clark SD, Kenakin TP, Gertz S, Hassler C, Gay EA, Langston TL, Reinscheid RK, Runyon SP (2017) Identification of the first biased NPS receptor agonist that retains anxiolytic and memory promoting effects with reduced levels of locomotor stimulation. Neuropharmacology 118:69-78.

Dabrowska J, Hazra R, Ahern TH, Guo JD, McDonald AJ, Mascagni F, Muller JF, Young LJ, Rainnie DG (2011) Neuroanatomical evidence for reciprocal regulation of the corticotrophin-releasing factor and oxytocin systems in the hypothalamus and the bed nucleus of the stria terminalis of the rat: implications for balancing stress and affect. Psychoneuroendocrinology 36:1312-1326.

de Jong TR, Beiderbeck DI, Neumann ID (2014) Measuring virgin female aggression in the female intruder test (FIT): effects of oxytocin, estrous cycle, and anxiety. PLoS One 9:e91701.

de Jong TR, Menon R, Bludau A, Grund T, Biermeier V, Klampfl SM, Jurek B, Bosch OJ, Hellhammer J, Neumann ID (2015) Salivary oxytocin concentrations in response to running, sexual self-stimulation, breastfeeding and the TSST: the Regensburg Oxytocin Challenge (ROC) study. Psychoneuroendocrinology 62:381-388.

Ebner K, Rjabokon A, Pape HC, Singewald N (2011) Increased in vivo release of neuropeptide $S$ in the amygdala of freely moving rats after local depolarisation and emotional stress. Amino Acids 41:991-996.

Eliava M, Melchior M, Knobloch-Bollmann HS, Wahis J, da Silva Gouveia M, Tang Y, Ciobanu AC, Triana Del Rio R, Roth LC, Althammer F, Chavant V, Goumon Y, Gruber T, Petit-Demoulière N, Busnelli M, Chini B, Tan LL, Mitre M, Froemke RC, Chao MV, et al. (2016) A new population of parvocellular oxytocin neurons controlling magnocellular neuron activity and inflammatory pain processing. Neuron 89:1291-1304.

Erdmann F, Kügler S, Blaesse P, Lange MD, Skryabin BV, Pape HC, Jüngling K (2015) Neuronal expression of the human neuropeptide S receptor NPSR1 identifies NPS-induced calcium signaling pathways. PLoS One 10:e0117319.

Fisher TE, Bourque CW (1996) Calcium-channel subtypes in the somata and axon terminals of magnocellular neurosecretory cells. Trends Neurosci 19:440-444.

Gomez JL, Bonaventura J, Lesniak W, Mathews WB, Sysa-Shah P, Rodriguez LA, Ellis RJ, Richie CT, Harvey BK, Dannals RF, Pomper MG, Bonci A, Michaelides M (2017) Chemogenetics revealed: DREADD occupancy and activation via converted clozapine. Science 357:503-507.

Gross C, Hen R (2004) The developmental origins of anxiety. Nat Rev Neurosci 5:545-552.

Grund T, Neumann ID (2017) Neuropeptide S induces acute anxiolysis by phospholipase C-dependent signaling within the medial amygdala. Neuropsychopharmacology. Advance online publication. Retrieved Aug. 14, 2017. doi: 10.1038/npp.2017.169. 
Guez-Barber D, Fanous S, Harvey BK, Zhang Y, Lehrmann E, Becker KG, Picciotto MR, Hope BT (2012) FACS purification of immunolabeled cell types from adult rat brain. J Neurosci Methods 203:10-18.

Johnson ZV, Young LJ (2017) Oxytocin and vasopressin neural networks: implications for social behavioral diversity and translational neuroscience. Neurosci Biobehav Rev 76:87-98.

Jones BE, Yang TZ (1985) The efferent projections from the reticular formation and the locus coeruleus studied by anterograde and retrograde axonal transport in the rat. J Comp Neurol 242:56-92.

Jüngling K, Seidenbecher T, Sosulina L, Lesting J, Sangha S, Clark SD, Okamura N, Duangdao DM, Xu YL, Reinscheid RK, Pape HC (2008) Neuropeptide S-mediated control of fear expression and extinction: role of intercalated GABAergic neurons in the amygdala. Neuron 59:298-310.

Jüngling K, Liu X, Lesting J, Coulon P, Sosulina L, Reinscheid RK, Pape HC (2012) Activation of neuropeptide S-expressing neurons in the locus coeruleus by corticotropin-releasing factor. J Physiol 590:3701-3717.

Jurek B, Slattery DA, Maloumby R, Hillerer K, Koszinowski S, Neumann ID, van den Burg EH (2012) Differential contribution of hypothalamic MAPK activity to anxiety-like behaviour in virgin and lactating rats. PLoS One 7:e37060.

Jurek B, Slattery DA, Hiraoka Y, Liu Y, Nishimori K, Aguilera G, Neumann ID, van den Burg EH (2015) Oxytocin regulates stress-induced Crf gene transcription through CREB-regulated transcription coactivator 3. J Neurosci 35:12248-12260.

Kessler RC, Brandenburg N, Lane M, Roy-Byrne P, Stang PD, Stein DJ, Wittchen HU (2005) Rethinking the duration requirement for generalized anxiety disorder: evidence from the National Comorbidity Survey Replication. Psychol Med 35:1073-1082.

Knobloch HS, Charlet A, Hoffmann LC, Eliava M, Khrulev S, Cetin AH, Osten P, Schwarz MK, Seeburg PH, Stoop R, Grinevich V (2012) Evoked axonal oxytocin release in the central amygdala attenuates fear response. Neuron 73:553-566.

Lambert RC, Dayanithi G, Moos FC, Richard P (1994) A rise in the intracellular $\mathrm{Ca}^{2+}$ concentration of isolated rat supraoptic cells in response to oxytocin. J Physiol 478:275-287.

Landgraf R, Neumann ID (2004) Vasopressin and oxytocin release within the brain: a dynamic concept of multiple and variable modes of neuropeptide communication. Front Neuroendocrinol 25:150-176.

Leonard SK, Ring RH (2011) Immunohistochemical localization of the neuropeptide $\mathrm{S}$ receptor in the rat central nervous system. Neuroscience 172:153-163.

Liao Y, Lu B, Ma Q, Wu G, Lai X, Zang J, Shi Y, Liu D, Han F, Zhou N (2016) Human neuropeptide $S$ receptor is activated via a Galphaq protein-biased signaling cascade by a human neuropeptide $S$ analog lacking the C-terminal 10 residues. J Biol Chem 291:7505-7516.

Li W, Chang M, Peng YL, Gao YH, Zhang JN, Han RW, Wang R (2009) Neuropeptide S produces antinociceptive effects at the supraspinal level in mice. Regul Pept 156:90-95.

Li Y, Schmidt-Edelkraut U, Poetz F, Oliva I, Mandl C, Hölzl-Wenig G, Schönig K, Bartsch D, Ciccolini F (2015) $\gamma$-Aminobutyric A receptor $(\mathrm{GABA}(\mathrm{A}) \mathrm{R})$ regulates aquaporin 4 expression in the subependymal zone: relevance to neural precursors and water exchange. J Biol Chem 290:43434355.

Livak KJ, Schmittgen TD (2001) Analysis of relative gene expression data using real-time quantitative PCR and the 2(T)(-Delta Delta C) method. Methods 25:402-408.

Lobo MK, Karsten SL, Gray M, Geschwind DH, Yang XW (2006) FACSarray profiling of striatal projection neuron subtypes in juvenile and adult mouse brains. Nat Neurosci 9:443-452.

Loughlin SE, Foote SL, Grzanna R (1986) Efferent projections of nucleus locus coeruleus: morphologic subpopulations have different efferent targets. Neuroscience 18:307-319.

Ludwig M, Sabatier N, Bull PM, Landgraf R, Dayanithi G, Leng G (2002) Intracellular calcium stores regulate activity-dependent neuropeptide release from dendrites. Nature 418:85-89.

Lukas M, Toth I, Veenema AH, Neumann ID (2013) Oxytocin mediates rodent social memory within the lateral septum and the medial amygdala depending on the relevance of the social stimulus: male juvenile versus female adult conspecifics. Psychoneuroendocrinology 38:916-926.

MacLaren DA, Browne RW, Shaw JK, Krishnan Radhakrishnan S, Khare P, España RA, Clark SD (2016) Clozapine N-oxide administration pro- duces behavioral effects in Long-Evans rats: implications for designing DREADD experiments. eNeuro 3:ENEURO.0219-16.2016.

Manning M, Misicka A, Olma A, Bankowski K, Stoev S, Chini B, Durroux T, Mouillac B, Corbani M, Guillon G (2012) Oxytocin and vasopressin agonists and antagonists as research tools and potential therapeutics. J Neuroendocrinol 24:609-628.

Meis S, Bergado-Acosta JR, Yanagawa Y, Obata K, Stork O, Munsch T (2008) Identification of a neuropeptide $S$ responsive circuitry shaping amygdala activity via the endopiriform nucleus. PLoS One 3:e2695.

Neumann ID (2007) Stimuli and consequences of dendritic release of oxytocin within the brain. Biochem Soc Trans 35:1252-1257.

Neumann ID (2008) Brain oxytocin: a key regulator of emotional and social behaviours in both females and males. J Neuroendocrinol 20:858-865.

Neumann ID, Landgraf R (2012) Balance of brain oxytocin and vasopressin: implications for anxiety, depression, and social behaviors. Trends Neurosci 35:649-659.

Neumann ID, Slattery DA (2016) Oxytocin in general anxiety and social fear: a translational approach. Biol Psychiatry 79:213-221.

Neumann ID, Torner L, Wigger A (2000) Brain oxytocin: differential inhibition of neuroendocrine stress responses and anxiety-related behaviour in virgin, pregnant and lactating rats. Neuroscience 95:567-575.

Neumann ID, Torner L, Toschi N, Veenema AH (2006) Oxytocin actions within the supraoptic and paraventricular nuclei: differential effects on peripheral and intranuclear vasopressin release. Am J Physiol Regul Int Comp Physiol 291:R29-R36.

Neumann I, Russell JA, Landgraf R (1993) Oxytocin and vasopressin release within the supraoptic and paraventricular nuclei of pregnant, parturient and lactating rats: a microdialysis study. Neuroscience 53:65-75.

Okamura N, Habay SA, Zeng J, Chamberlin AR, Reinscheid RK (2008) Synthesis and pharmacological in vitro and in vivo profile of 3-oxo-1, 1-diphenyl-tetrahydro-oxazolo[3,4-a]pyrazine-7-carboxylic acid 4-fluorobenzylamide (SHA 68), a selective antagonist of the neuropeptide $\mathrm{S}$ receptor. J Pharmacol Exp Ther 325:893-901.

Olson BR, Drutarosky MD, Chow MS, Hruby VJ, Stricker EM, Verbalis JG (1991) Oxytocin and an oxytocin agonist administered centrally decrease food intake in rats. Peptides 12:113-118.

Pape HC, Jüngling K, Seidenbecher T, Lesting J, Reinscheid RK (2010) Neuropeptide S: a transmitter system in the brain regulating fear and anxiety. Neuropharmacology 58:29-34.

Paxinos G, Watson C (1998) The rat brain in stereotaxic coordinates, Ed 7. San Diego: Academic.

Reinscheid RK, Xu YL, Okamura N, Zeng J, Chung S, Pai R, Wang Z, Civelli O (2005) Pharmacological characterization of human and murine neuropeptide S receptor variants. J Pharmacol Exp Ther 315:1338-1345.

Ruzza C, Rizzi A, Trapella C, Pela’ M, Camarda V, Ruggieri V, Filaferro M, Cifani C, Reinscheid RK, Vitale G, Ciccocioppo R, Salvadori S, Guerrini R, Calo' G (2010) Further studies on the pharmacological profile of the neuropeptide S receptor antagonist SHA 68. Peptides 31:915-925.

Ruzza C, Asth L, Guerrini R, Trapella C, Gavioli EC (2015) Neuropeptide S reduces mouse aggressiveness in the resident/intruder test through selective activation of the neuropeptide $S$ receptor. Neuropharmacology 97 : $1-6$.

Slattery DA, Naik RR, Grund T, Yen YC, Sartori SB, Füchsl A, Finger BC, Elfving B, Nordemann U, Guerrini R, Calo G, Wegener G, Mathé AA, Singewald N, Czibere L, Landgraf R, Neumann ID (2015) Selective breeding for high anxiety introduces a synonymous SNP that increases neuropeptide S receptor activity. J Neurosci 35:4599-4613.

Smith KL, Patterson M, Dhillo WS, Patel SR, Semjonous NM, Gardiner JV, Ghatei MA, Bloom SR (2006) Neuropeptide S stimulates the hypothalamopituitary-adrenal axis and inhibits food intake. Endocrinology 147:35103518.

Swanson LW, Sawchenko PE (1980) Paraventricular nucleus: a site for the integration of neuroendocrine and autonomic mechanisms. Neuroendocrinology 31:410-417.

Swanson LW, Sawchenko PE (1983) Hypothalamic integration: organization of the paraventricular and supraoptic nuclei. Annu Rev Neurosci 6:269-324.

Torner L, Plotsky PM, Neumann ID, de Jong TR (2017) Forced swimminginduced oxytocin release into blood and brain: effects of adrenalectomy and corticosterone treatment. Psychoneuroendocrinology 77:165-174.

van den Burg EH, Stindl J, Grund T, Neumann ID, Strauss O (2015) Oxytocin stimulates extracellular $\mathrm{Ca}(2+)$ influx through TRPV2 channels in 
hypothalamic neurons to exert its anxiolytic effects. Neuropsychopharmacology 40:2938-2947.

Viviani D, Charlet A, van den Burg E, Robinet C, Hurni N, Abatis M, Magara F, Stoop R (2011) Oxytocin selectively gates fear responses through distinct outputs from the central amygdala. Science 333:104-107.

Waldherr M, Neumann ID (2007) Centrally released oxytocin mediates mating-induced anxiolysis in male rats. Proc Natl Acad Sci U S A 104:16681-16684.

Xu YL, Reinscheid RK, Huitron-Resendiz S, Clark SD, Wang Z, Lin SH, Brucher FA, Zeng J, Ly NK, Henriksen SJ, de Lecea L, Civelli O (2004) Neuropeptide S: a neuropeptide promoting arousal and anxiolytic-like effects. Neuron 43:487-497.

Xu YL, Gall CM, Jackson VR, Civelli O, Reinscheid RK (2007) Distribution of neuropeptide $S$ receptor mRNA and neurochemical characteristics of neuropeptide S-expressing neurons in the rat brain. J Comp Neurol 500:84-102.

Yoshida M, Takayanagi Y, Inoue K, Kimura T, Young LJ, Onaka T, Nishimori K (2009) Evidence that oxytocin exerts anxiolytic effects via oxytocin receptor expressed in serotonergic neurons in mice. J Neurosci 29:2259-2271.

Zoicas I, Slattery DA, Neumann ID (2014) Brain oxytocin in social fear conditioning and its extinction: involvement of the lateral septum. Neuropsychopharmacology 39:3027-3035.

Zoicas I, Menon R, Neumann ID (2016) Neuropeptide S reduces fear and avoidance of con-specifics induced by social fear conditioning and social defeat, respectively. Neuropharmacology 108:284-291. 